\title{
Tolerância À Interferência de Plantas Competidoras e Habilidade de SupRessão POR Genótipos de SoJa - II. Resposta de VARIÁVeIS DE PROdUTIVIDAde ${ }^{1}$
}

\author{
Tolerance to Interference of Competing Plants and Suppressive Ability by Soybean Genotypes- \\ II. Response of Yield Variables
}

LAMEGO, F.P. ${ }^{2}$, FLECK, N.G. ${ }^{3}$, BIANCHI, M.A. ${ }^{4}$ e SCHAEDLER, C.E. ${ }^{5}$

\begin{abstract}
RESUMO - As perdas de produtividade das culturas em decorrência da competição de plantas concorrentes geralmente aumentam quanto mais semelhantes forem suas caracteristicas morfofisiológicas. O objetivo deste trabalho foi avaliar os efeitos da competição de cultivares de soja, simulando espécies daninhas dicotiledôneas, sobre cultivares de soja portadores de características diferenciais de planta. Para isso, conduziu-se um experimento em campo, em Eldorado do Sul-RS. Os fatores e tratamentos comparados foram: três condições de competição (ausência de plantas de soja concorrentes e presença de plantas concorrentes do cultivar de soja BRS 205 ou Cobb); e quatro cultivares reagentes de soja à competição (IAS 5, BR-16, CD 205 e Fepagro RS-10). Avaliaram-se variáveis relacionadas à produtividade dos cultivares e outras correlatas. Características dissimilares em plantas de cultivares de soja, como estatura e ciclo, resultaram em habilidade competitiva diferenciada com plantas concorrentes. O cultivar de soja CD 205, de estatura elevada e ciclo tardio, mostrou alta habilidade competitiva; IAS 5, de baixa estatura e ciclo precoce, apresentou baixa tolerância à competição, enquanto BR-16 e Fepagro RS-10 são intermediários. Cultivares com elevada habilidade competitiva, além de tolerarem a competição, preservando o potencial de produtividade, também suprimem a produção de grãos das plantas concorrentes.
\end{abstract}

Palavras-chave: competição, cultivares de soja, características de planta, habilidade competitiva, produtividade de grãos.

\begin{abstract}
Due to concurrent plant competition, crop yield losses generally increase as their morphophysiological characteristics become more similar. The objective of this research was to evaluate the competitive effects of soybean cultivars mimicking dicotyledonous weed species on soybean cultivars holding dissimilar plant characteristics. Thus, a field experiment was carried out in Eldorado do Sul-RS. The factors and treatments compared were: three competition conditions (absence of competing plants and presence of the soybean cultivar "BRS 205" or "Cobb"), and four soybean cultivars reagents to competition ("IAS 5", "BR-16", "CD 205", and "Fepagro RS-10"). Variables related to cultivar yield and other correlatives were evaluated. Dissimilar characteristics in soybean plant cultivars such as height and maturity length, resulted in differentiated competitive ability with concurrent plants. The cultivar CD 205 of high stature and late maturity showed high competitive ability while IAS 5, of low stature and early maturity, showed low tolerance to competition, and BR-16 and Fepagro RS-10 showed intermediate tolerance. Soybean cultivars holding high competitive ability as well as tolerance to competition, thus preserving their yield potential, also suppressed grain yield of competing plants.
\end{abstract}

Key words: competition, soybean cultivars, plant characteristics, competitive ability, crop yield.

Recebido para publicação em 18.4.2004 e na forma revisada em 17.12.2004.

Eng.-Agra ${ }^{\text {. }}$, aluna do Programa de Pós-Graduação em Fitotecnia da Universidade Federal do Rio Grande do Sul - UFRGS, Caixa Postal 15100, 91501-970 Porto Alegre-RS, <fabilamego@yahoo.com.br>; ${ }^{3}$ Eng.-Agr., Ph.D., Prof. do Departamento de Plantas de Lavoura da Faculdade de Agronomia da UFRGS, Bolsista do CNPq; ${ }^{4}$ Eng.-Agr., M.S., aluno do Programa de Pós-Graduação em Fitotecnia da UFRGS; ${ }^{5}$ Bolsista de Iniciação Científica do CNPq. 


\section{INTRODUÇÃO}

A presença de plantas daninhas em lavouras de soja afeta negativamente o desenvolvimento da cultura, geralmente causando redução na produtividade de grãos. Usualmente, as perdas de produtividade decorrentes da competição de plantas concorrentes tendem a ser mais elevadas quanto mais semelhantes forem os indivíduos, alcançando estresse máximo dentro da mesma espécie, pois plantas vizinhas disputarão recursos ao ocuparem o mesmo nicho ecológico (Radosevich et al., 1997).

Nas relações de competição, as culturas podem responder de duas maneiras às infestações de plantas daninhas: tolerância, que consiste na habilidade delas em manter a produtividade em situação de competição, ou supressão, que se refere à capacidade da cultura em reduzir o crescimento de plantas daninhas por efeito de interferência (Jannink et al., 2000). Em soja, plantas daninhas que cresceram abaixo do dossel da cultura foram suprimidas, porém a soja não tolerou a competição de Xanthium strumarium (carrapichão), respondendo com redução no crescimento e na produtividade de grãos (Regnier \& Stoller, 1989).

$\mathrm{O}$ incremento da capacidade competitiva das culturas associa-se a variáveis como maior tamanho de sementes e emergência precoce, rápido fechamento de entrelinhas e maior estatura de planta (Liebman et al., 2001). Em soja, estatura de planta e ciclo de desenvolvimento associam-se à maior competitividade com plantas daninhas (Bennett \& Shaw, 2000). A habilidade da soja em competir com plantas concorrentes, principalmente durante o periodo vegetativo, garante-1he vantagens na busca por recursos e na sintese de fotoassimilados, os quais serão canalizados para o enchimento de grãos durante o período reprodutivo.

Os efeitos decorrentes da competição de plantas daninhas sobre características de plantas cultivadas podem comprometer o desenvolvimento de estruturas reprodutivas e, conseqüentemente, afetar os componentes da produtividade de grãos. Dentre estes, em soja, o número de legumes é o mais responsivo a alterações causadas pelo estresse da competição de espécies concorrentes, enquanto o número de grãos por legume e o peso do grão possuem maior controle genético individual, mostrando pequena amplitude de variação por causa de ambiente (Board et al., 1995). Contudo, diversos trabalhos relatam o efeito negativo da competição de plantas daninhas sobre os componentes da produtividade da soja. Nesse aspecto, a competição de Euphorbia dentata causou redução de 40\% no número de legumes por planta da cultura (Juan et al., 2003). Também, os números de grãos por legume e de legumes por área foram reduzidos quando a soja sofreu competição de Euphorbia heterophylla (Chemalle \& Fleck, 1982).

Este trabalho teve por objetivo avaliar os efeitos da competição de cultivares de soja, simulando infestação de plantas daninhas dicotiledôneas, sobre variáveis como produtividade de grãos e seus componentes, em cultivares de soja portadores de características dissimilares de plantas.

\section{MATERIAL E MÉTODOS}

Um experimento foi conduzido em campo no ano agrícola 2002/03, na Estação Experimental Agronômica da Universidade Federal do Rio Grande do Sul (EEA/UFRGS), em Eldorado do Sul - RS. O solo da área experimental é classificado como Latossolo Vermelho Distrófico típico, pertencendo à unidade de mapeamento São Jerônimo (Embrapa, 1999).

Para implantação do experimento foram selecionados quatro cultivares de soja, os quais foram testados como reagentes à interferência de outros dois cultivares, usados como simuladores de plantas daninhas dicotiledôneas. O critério para escolha dos genótipos baseou-se, especialmente, em características como estatura de planta e ciclo de desenvolvimento, de modo que divergissem nesses caracteres.

O delineamento experimental utilizado no estudo foi o de blocos casualizados, com quatro repetições, com parcelas subdivididas, em que diferentes condições de competição foram dispostas nas parcelas principais e os cultivares reagentes de soja nas subparcelas. Os fatores e tratamentos comparados foram: três condições de competição (ausência de cultivares de soja concorrentes; presença do cultivar 
competidor BRS 205 ou Cobb); e quatro cultivares reagentes de soja (IAS 5, BR-16, CD 205 e Fepagro RS-10). Cada unidade experimental mediu $16 \mathrm{~m}^{2}(4 \times 4 \mathrm{~m})$, constando de dez fileiras de soja espaçadas de $0,4 \mathrm{~m}$, sendo a área útil estipulada em $3,84 \mathrm{~m}^{2}(1,6 \times 2,4 \mathrm{~m})$.

O experimento foi conduzido com o solo manejado sob sistema de semeadura direta, em área onde houve cultivo anterior da associação de aveia-preta (Avena strigosa) e ervilhaca (Vicia sativa). O manejo das espécies de cobertura e da vegetação espontânea foi realizado através de duas aplicações do herbicida glyphosate (nas doses de 1.080 e $900 \mathrm{~g}$ de equivalente ácido $\mathrm{ha}^{-1}$, respectivamente). $\mathrm{O}$ controle seletivo em pós-emergência das plantas daninhas foi feito através da aplicação dos herbicidas clethodim $\left(240 \mathrm{~g} \mathrm{ha}^{-1}\right)$, acrescido do adjuvante Joint Oil ( $0,5 \%$ volume/volume), para eliminar espécies daninhas gramineas, e bentazon (600 $\left.\mathrm{g} \mathrm{ha}^{-1}\right)$, para controlar espécies dicotiledôneas.

A adubação do solo foi efetuada 13 dias antes da semeadura, por ocasião da rolagem mecânica da cobertura vegetal, realizada entre as duas dessecações. Realizou-se a distribuição do adubo a lanço, em superficie, aplicandose $300 \mathrm{~kg} \mathrm{ha}^{-1}$ da fórmula 5-30-15, o que correspondeu à adição de 15,90 e $45 \mathrm{~kg} \mathrm{ha}^{-1}$ de $\mathrm{N}$, $\mathrm{P}_{2} \mathrm{O}_{5}$ e $\mathrm{K}_{2} \mathrm{O}$, respectivamente. As quantidades de nutrientes necessárias foram determinadas com base no resultado da análise de solo.

Antecedendo à semeadura, as sementes de soja foram inoculadas com estirpes de Bradyrhizobium japonicum (SEMIA 5019). A semeadura da soja foi realizada no dia 6 de novembro de 2002, sendo os cultivares concorrentes (BRS 205 e Cobb) semeados no sentido transversal ao das linhas dos cultivares reagentes, também no espaçamento de 0,4 $\mathrm{m}$. A densidade de semeadura dos cultivares reagentes foi ajustada de acordo com seu poder germinativo, objetivando-se alcançar densidade de 40 plantas $\mathrm{m}^{-2}$, enquanto para os competidores objetivou-se densidade de 20 plantas $\mathrm{m}^{-2}$. Durante os meses de janeiro e fevereiro foram realizadas, quando necessárias, suplementações hídricas por meio de irrigações por aspersão.

As variáveis avaliadas nos cultivares reagentes e nos simuladores de plantas daninhas foram: produtividade biológica aparente da soja (PBA) nos estádios de desenvolvimento $R_{6}$ e $R_{8}$ (com base na escala proposta por Costa $\&$ Marchezan, 1982), indice de colheita aparente (ICA), componentes da produtividade de grãos (número de legumes por área, número de grãos por legume e peso do grão) e produtividade de grãos. Para obtenção da PBA foram coletadas cinco plantas, seqüencialmente, em duas fileiras de soja, em área não destinada à produtividade de grãos, medindo-se a área de solo ocupada pela amostra. As plantas foram secas em estufa a $60{ }^{\circ} \mathrm{C}$, até se obter massa constante, sendo então pesadas. A PBA compreendeu o somatório das massas secas das partes aéreas das plantas, incluindo legumes e grãos. A divisão da massa seca dos grãos pela produção biológica aparente forneceu o ICA (expresso em porcentagem). Em dez plantas coletadas no estádio $R_{8}$ de cada cultivar foram realizadas as determinações dos componentes de produtividade. O peso do grão (representado pela massa de 1.000 grãos) foi obtido a partir da massa de 400 grãos separados aleatoriamente do total de grãos colhidos na área útil de cada subparcela, com umidade padronizada para teor de $13 \%$. Os valores do componente número de legumes foram expressos em unidade de área $\left(\mathrm{m}^{2}\right)$.

Por ocasião da colheita das plantas dos cultivares reagentes, 154 dias após a emergência (DAE) para os precoces e $161 \mathrm{DAE}$ para os tardios, determinou-se a produtividade de grãos em área de $3,84 \mathrm{~m}^{2}$. Após pesagem dos grãos, foi determinada sua umidade e, posteriormente, os pesos foram padronizados para $13 \%$ de umidade. Os cultivares competidores, precoce e tardio, foram colhidos nas mesmas épocas dos demais cultivares.

A partir da produtividade de grãos dos cultivares reagentes e competidores calculou-se o índice de uso eficiente da terra (UET), com o objetivo de estabelecer os graus de complementaridade entre os cultivares associados e sua participação relativa na produtividade total de grãos, quando em competição. Nesse sentido, utilizou-se a equação referida por Radosevich et al. (1997), em que UET $=$ UET $_{r}+$ $\mathrm{UET}_{\mathrm{s}}$, sendo: $\mathrm{UET}_{\mathrm{r}}=\mathrm{PR}_{\mathrm{A}} / \mathrm{PR}_{\mathrm{M}}$ e UET $=\mathrm{PS}_{\mathrm{A}} / \mathrm{PS}_{\mathrm{M}}$. No caso, tem-se: $\mathrm{UET}_{\mathrm{r}}=\mathrm{UET}$ parcial do cultivar reagente, $\mathrm{PR}_{\mathrm{A}}=$ produtividade de grãos do cultivar reagente $(R)$ quando em associação e 
$\mathrm{PR}_{\mathrm{M}}=$ produtividade de grãos do cultivar $\mathrm{R}$ quando em monocultivo. Adicionalmente, temse: $\mathrm{UET}_{\mathrm{s}}=\mathrm{UET}$ parcial do cultivar simulador; $\mathrm{PS}_{\mathrm{A}}=$ produtividade de grãos do cultivar simulador (S) quando em associação; e $\mathrm{PS}_{\mathrm{M}}=$ produtividade de grãos do cultivar $\mathrm{S}$ quando em monocultivo. A contribuição relativa de cada cultivar reagente para o UET total da respectiva associação foi obtida pela divisão do UET pelo UET, sendo os valores expressos em porcentagem.

Os dados obtidos no experimento foram submetidos à análise de variância, através do teste F, adotando-se como limites de aceitação o nivel de $5 \%$ de probabilidade para significância de efeitos individuais dos fatores e o de $10 \%$ para efeitos de interação de fatores (Riboldi, 1993). As médias dos tratamentos foram comparadas aplicando-se o teste de Duncan, adotando-se o nivel de 5\% de probabilidade. Aos dados obtidos para a variável produtividade de grãos dos cultivares reagentes também foram calculadas perdas (P) percentuais, relativamente às parcelas testemunhas (ausência de cultivares concorrentes $): \mathrm{P}(\%)=((\mathrm{Pa}-\mathrm{Pp}) / \mathrm{Pa})^{*} 100$, em que: $\mathrm{Pa} \mathrm{e}$ $\mathrm{Pp}=$ produtividades do cultivar reagente na ausência e na presença de cultivar simulador, respectivamente.

Para análise dos resultados dos cultivares simuladores, os dados foram submetidos à análise de variância e ao teste de Dunnett, ambos em nivel de $5 \%$ de probabilidade. Neste caso, as médias dos simuladores, em associação com os cultivares reagentes, foram comparadas às do tratamento-padrão (simuladores em monocultivo). Os dados de UET foram submetidos à análise de variância, através do teste $\mathrm{F}$, adotando-se o nivel de $5 \%$ de probabilidade. As médias dos tratamentos foram comparadas aplicando-se o teste de Duncan, em nivel de $5 \%$ de probabilidade. A análise estatística foi realizada com auxílio do programa computacional SAS (SAS, 1989).

\section{RESULTADOS E DISCUSSÃO}

Para produtividade biológica aparente (PBA), avaliada nos estádios $R_{6}$ e $R_{8}$ da soja, não se constatou interação para os fatores estudados. Contudo, em $\mathrm{R}_{6}$, foram significativas as diferenças entre os cultivares (dados não mostrados). O cultivar BR-16 alcançou a maior PBA nesse estádio, enquanto IAS 5 foi o menos produtivo, permanecendo os cultivares tardios em posição intermediária e em nível equivalente. Já no estádio $R_{8}$ houve significância estatística apenas entre as condições de competição (Figura 1). Na ausência de cultivares simuladores, a PBA superou amplamente os valores encontrados em ambas as condições de presença de competidores, os quais foram equivalentes. Entretanto, em valores absolutos, a presença de Cobb induziu redução adicional de $8,5 \%$ na $\mathrm{PBA}$, em comparação com BRS 205.

A PBA indica a quantidade de massa aérea acumulada pelas plantas durante seu ciclo de desenvolvimento, a qual é canalizada, potencialmente, para a produção de grãos (Donald, 1962). Estresses enfrentados durante o desenvolvimento da cultura, como o decorrente da competição de plantas concorrentes, podem alterar a quantidade de massa seca acumulada pelas plantas. Em soja, por exemplo, a presença de Euphorbia dentata causou redução de $57 \%$ na massa seca da cultura (Juan et al., 2003).

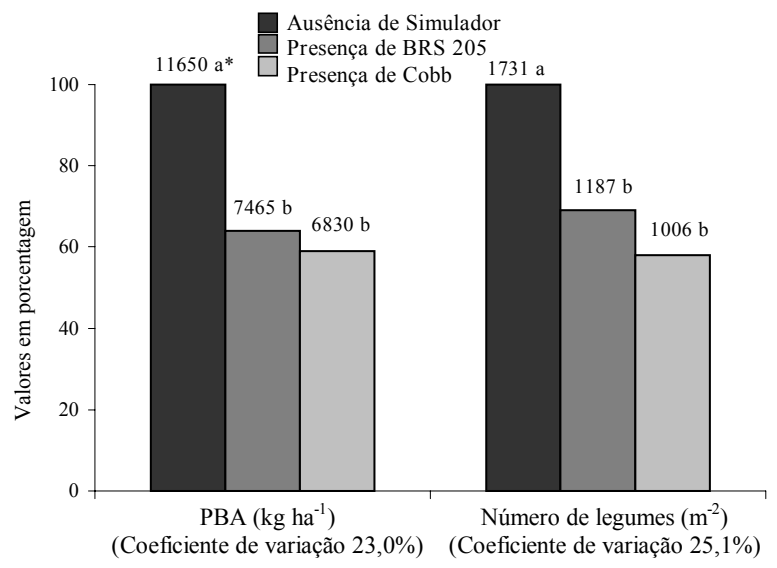

* Médias seguidas de mesma letra, em cada característica, não diferem pelo teste de Duncan a $5 \%$ de probabilidade.

Figura 1 - Produtividade biológica aparente (PBA) no estádio fenológico $\mathrm{R}_{8}$ e número de legumes por área, médias dos cultivares de soja IAS 5, BR-16, CD 205 e Fepagro RS-10, reagentes à competição ou não dos cultivares BRS 205 e Cobb, simuladores de plantas daninhas dicotiledôneas. EEA/ UFRGS, Eldorado do Sul-RS, 2002/03. 
Para PBA estimada no estádio $\mathrm{R}_{8}$, embora os cultivares simuladores apresentassem características dissimilares, os cultivares reagentes responderam na mesma magnitude à competição que lhes foi imposta. É possivel que o limitado número de plantas amostradas tenha contribuído, em parte, para a variabilidade encontrada. Provavelmente, uma área mais abrangente para coleta de plantas atenuasse o erro experimental.

Em relação ao número de legumes produzidos por área pelos cultivares reagentes, as condições de competição também induziram diferenças na variável, a qual foi igualmente afetada por ambos os genótipos competidores (Figura 1). Neste caso, considerados os valores absolutos obtidos, a presença do simulador Cobb reduziu a variável em mais $15,2 \%$, comparativamente a BRS 205. Para o número de grãos por legume dos cultivares reagentes, houve efeito de interação para os fatores condições de competição e cultivares reagentes (Tabela 1). Na ausência de simuladores, o cultivar CD 205 apresentou o maior número de grãos por legume, e o RS-10, o menor valor. Quando da presença do simulador BRS 205, CD 205 manteve o maior valor absoluto, superando estatisticamente IAS 5. Por outro lado, na presença de Cobb, não houve diferenças entre os cultivares para o componente em questão. Os cultivares IAS 5, BR-16 e RS-10 mantiveram estatisticamente inalterado o número de grãos por legume nas três condições de competição, enquanto CD 205 sofreu redução no componente em função da presença dos cultivares competidores.
Quanto ao peso do grão, houve diferenças significativas apenas entre os cultivares reagentes. O cultivar RS-10 apresentou o maior peso do grão, enquanto CD 205 mostrou o menor valor. Contudo, este componente da produtividade não sofreu efeito diferencial imposto pelas condições de competição.

No que se refere à produtividade de grãos, ocorreu interação para os fatores investigados (Tabela 2). Os quatro cultivares reagentes mostraram o mesmo comportamento diante das condições de competição estudadas: produziram mais na ausência de cultivares simuladores, diminuíram a produtividade na presença do simulador BRS 205 e sofreram a mais forte redução da variável quando foram submetidos à competição de Cobb. Por outro lado, na ausência de competição, os quatro cultivares apresentaram potenciais de produtividade de grãos equivalentes. O cultivar CD 205 alcançou a maior produtividade de grãos na presença do simulador BRS 205, enquanto IAS 5 foi o mais afetado pela competição deste genótipo. Quando o simulador testado foi Cobb, CD 205 manteve a posição de maior produtividade, ao passo que IAS 5 continuou sendo o mais afetado, sofrendo redução média de $65 \%$ na variável, quando comparada à ausência de competição. Cabe ressaltar que os cultivares tardios CD 205 e RS-10 foram, proporcionalmente, os menos afetados pela presença de BRS 205, em comparação à competição ocasionada por Cobb. Contudo, em termos proporcionais, o cultivar RS-10 foi o que mostrou maior queda percentual de produtividade quando passou da condição de competição com BRS 205 para a de Cobb.

Tabela 1 - Número de grãos por legume dos cultivares de soja reagentes à competição ou não dos cultivares BRS 205 e Cobb, simuladores de plantas daninhas. EEA/UFRGS, Eldorado do Sul-RS, 2002/03

\begin{tabular}{|c|c|c|c|c|c|c|c|c|}
\hline \multirow{3}{*}{ Cultivar reagente } & \multicolumn{8}{|c|}{ Grãos por legume $\left(\mathrm{n}^{\mathrm{o}}\right)$} \\
\hline & \multicolumn{8}{|c|}{ Condições de competição } \\
\hline & \multicolumn{2}{|c|}{ Ausência de simulador } & \multicolumn{3}{|c|}{ Presença de BRS 205} & \multicolumn{3}{|c|}{ Presença de Cobb } \\
\hline IAS 5 & & $1,89 \quad \mathrm{BC}^{2 /}$ & $\mathrm{a}$ & 1,67 & B & & 1,90 & A \\
\hline BR-16 & a & $2,01 \quad \mathrm{~B}$ & a & 1,86 & $\mathrm{AB}$ & a & 1,94 & A \\
\hline CD 205 & $\mathrm{a}$ & $2,86 \quad \mathrm{~A}$ & $\mathrm{~b}$ & 2,27 & A & b & 2,23 & A \\
\hline Fepagro RS-10 & $\mathrm{a}$ & $1,51 \quad \mathrm{C}$ & $\mathrm{a}$ & 1,85 & $\mathrm{AB}$ & a & 1,95 & A \\
\hline Coeficiente de variacão (\%) & \multicolumn{8}{|c|}{15,57} \\
\hline
\end{tabular}

1/ Médias antecedidas de mesma letra minúscula, nas linhas, não diferem entre si pelo teste de Duncan a 5\% de probabilidade.

${ }^{2} /$ Médias seguidas de mesma letra maiúscula, nas colunas, não diferem entre si pelo teste de Duncan a 5\% de probabilidade. 
Tabela 2 - Produtividade de grãos dos cultivares de soja reagentes à competição ou não dos cultivares BRS 205 e Cobb, simuladores de plantas daninhas dicotiledôneas. EEA/UFRGS, Eldorado do Sul-RS, 2002/03

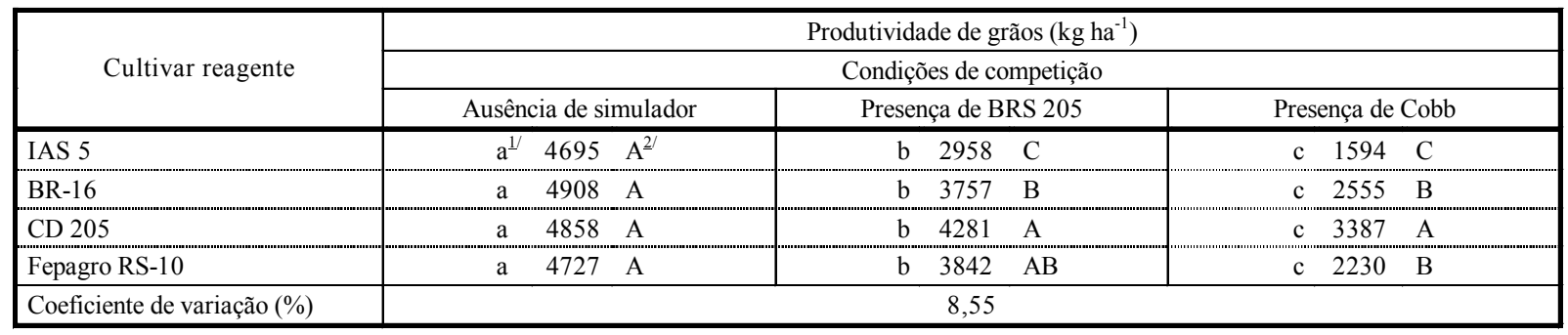

1/ Médias antecedidas de mesma letra minúscula, nas linhas, não diferem entre si pelo teste de Duncan a 5\% de probabilidade.

${ }^{2} /$ Médias seguidas de mesma letra maiúscula, nas colunas, não diferem entre si pelo teste de Duncan a $5 \%$ de probabilidade.

Calculando-se as reduções percentuais médias de produtividade de grãos (Tabela 2), os cultivares de soja reagentes à competição classificaram-se na seguinte ordem decrescente: IAS $5>$ RS-10 = BR-16 > CD 205. Portanto, CD 205 mostrou-se o mais tolerante ao estresse de competição, apresentando redução média de $21 \%$ na produtividade, enquanto IAS 5 foi o mais suscetivel (-51\%). Por sua vez, a competição exercida por ambos os genótipos simuladores afetou significativamente a produtividade média de grãos dos cultivares reagentes; a presença de Cobb promoveu redução de 49\% na variável, ao passo que BRS 205 a reduziu em $22 \%$.

O indice de colheita aparente (ICA) dos cultivares reagentes não foi afetado quando o competidor presente foi BRS 205; no entanto, a presença de Cobb reduziu o ICA. A maior interferência resultante da presença de Cobb na produtividade dos cultivares reagentes é corroborada pelo efeito verificado na eficiência de conversão da PBA acumulada pelas plantas para produção de grãos - o ICA. Embora para PBA em $R_{8}$ os cultivares reagentes tenham respondido de forma semelhante à associação com os simuladores, Cobb afetou o ICA, influenciando o enchimento de grãos dos cultivares reagentes.

Na cultura da soja, o ciclo longo e a estatura de planta elevada são características que costumam conferir maior habilidade competitiva à cultura (Bennett \& Shaw, 2000). Em geral, essas características correlacionam-se positivamente com a produção de grãos, pois têm relação com a maior quantidade de massa seca produzida, uma vez que a produção de fitomassa representa reserva potencial da planta para investir na formação de estruturas reprodutivas e no enchimento de grãos (Dybing, 1994). Nesse sentido, neste estudo, a PBA medida no estádio $R_{6}$ indicou valores superiores para BR-16 e CD 205 em relação a IAS 5, por exemplo, o que pressupõe que aqueles produziram maior quantidade de fitomassa, o que seria indicativo de plantas detentoras de maior potencial de sombreamento, logo, maior habilidade competitiva. Adicionalmente, esta característica não lhes comprometeu o potencial de produtividade, no qual ambas se equivaleram aos outros dois cultivares avaliados.

O efeito de estatura elevada de CD 205 e RS-10, possivelmente combinado com ciclo tardio, afetou a produtividade de grãos do simulador BRS 205, mostrando que aquele tipo de cultivar pode ser bastante competitivo com plantas concorrentes que apresentem baixa estatura e ciclo mais precoce. Em relação ao simulador Cobb, sua produtividade foi afetada, principalmente quando associada com CD 205, seguindo-se sua associação com BR-16. Esta última, embora na fase reprodutiva tenha apresentado estatura inferior à do simulador, mostrou características indicadoras de competitividade durante estádios iniciais de crescimento, enquanto Cobb, durante o mesmo período, apresentou lento crescimento. Em termos percentuais, o simulador BRS 205 sofreu reduções muito mais acentuadas de produtividade em decorrência da competição dos cultivares reagentes do que ocorreu com Cobb (Tabela 3). 
O UET para produtividade de grãos variou entre os cultivares reagentes, em função de suas associações com os simuladores (Tabelas 4 e 5). Os resultados assemelham-se aos obtidos para produtividade de grãos; o cultivar

Tabela 3 - Reduções percentuais da produtividade de grãos dos cultivares de soja BRS 205 e Cobb, simuladores de plantas daninhas dicotiledôneas, à competição de cultivares de soja reagentes. EEA/UFRGS, Eldorado do Sul-RS, 2002/03

\begin{tabular}{|l|c|c|}
\hline \multirow{2}{*}{ Cultivar reagente } & \multicolumn{2}{|c|}{$\begin{array}{r}\text { Redução (\%) da produtividade } \\
\text { dos simuladores }\end{array}$} \\
\cline { 2 - 3 } & BRS 205 & Cobb \\
\hline IAS 5 & $75 \mathrm{~b}^{\mathbf{1}}$ & $50 \mathrm{c}$ \\
\hline BR-16 & $77 \mathrm{~b}$ & $69 \mathrm{ab}$ \\
\hline CD 205 & $88 \mathrm{a}$ & $80 \mathrm{a}$ \\
\hline Fepagro RS-10 & $85 \mathrm{a}$ & $64 \mathrm{~b}$ \\
\hline Média & 81 & 66 \\
\hline Coeficiente de variação (\%) & 4,4 & 10,1 \\
\hline
\end{tabular}

1/ Médias seguidas de mesma letra, nas colunas, não diferem entre si pelo teste de Duncan a 5\% de probabilidade.
CD 205 foi o que contribuiu com a maior parcela para o UET da associação, enquanto IAS 5 foi o que teve menor participação. Com o simulador BRS 205, CD 205 e RS-10 foram os mais produtivos, contribuindo com as maiores parcelas para o UET das associações. Contudo, estes UETs não chegaram a se diferenciar em função de cultivar reagente associado, geralmente aproximando-se de 1,0, indicativo de uma complementaridade que tende à neutralidade. No caso das associações dos cultivares reagentes com Cobb, os UETs destes (entre 0,78 e 0,90 ) tendem a indicar que ocorreu intensa competição entre os genótipos, levando a uma complementaridade negativa entre eles. Em média, as contribuições relativas dos cultivares reagentes para o UET total das associações com os simuladores foram de $79 \%$ no caso de BRS 205 e de 60\% no caso de Cobb. Isso indica, novamente, maior potencial competitivo de Cobb, cultivar tardio e de estatura elevada, do que de BRS 205, cultivar precoce e de porte baixo.

Tabela 4 - Índice de uso eficiente da terra (UET) para cultivares de soja reagentes quando associados ao cultivar de soja BRS 205, simulador de plantas daninhas dicotiledôneas. EEA/UFRGS, Eldorado do Sul-RS, 2002/03

\begin{tabular}{|l|c|c|c|c|}
\hline \multirow{2}{*}{ Cultivar reagente } & \multicolumn{4}{|c|}{ Índice de uso eficiente da terra } \\
\cline { 2 - 5 } & $\mathrm{UET}_{\mathrm{r}}{ }^{1 /}$ & $\mathrm{UET}_{\mathrm{s}}{ }^{2 /}$ & $\mathrm{UET} \mathrm{da} \mathrm{associação}^{3 /}$ & Contribuição relativa (\%) $^{4 /}$ \\
\hline IAS 5 & $0,637 \mathrm{~b}^{5 /}$ & $0,286 \mathrm{a}$ & $0,923 \mathrm{a}$ & $69 \mathrm{c}$ \\
\hline BR-16 & $0,768 \mathrm{ab}$ & $0,228 \mathrm{ab}$ & $0,996 \mathrm{a}$ & $77 \mathrm{bc}$ \\
\hline CD 205 & $0,886 \mathrm{a}$ & $0,122 \mathrm{c}$ & $1,008 \mathrm{a}$ & $88 \mathrm{a}$ \\
\hline Fepagro RS-10 & $0,818 \mathrm{a}$ & $0,153 \mathrm{bc}$ & $0,971 \mathrm{a}$ & $84 \mathrm{ab}$ \\
\hline Média & 0,777 & 0,197 & 0,975 & 79 \\
\hline Coeficiente de variação (\%) & 0,9 & 24,7 & 5,9 & 6,8 \\
\hline
\end{tabular}

${ }^{1 /}$ UET parcial do cultivar de soja reagente à competição do simulador; ${ }^{2 /}$ UET parcial do cultivar simulador; ${ }^{3 /} \mathrm{UET}^{2}=\mathrm{UET}_{\mathrm{r}}+\mathrm{UET}_{\mathrm{s}}$; ${ }^{4 /}$ Contribuição relativa do cultivar de soja reagente para o UET total da associação com o cultivar BRS $205 ;{ }^{5 /}$ Médias seguidas de mesma letra, nas colunas, não diferem entre si pelo teste de Duncan a 5\% de probabilidade.

Tabela 5 - Índice de uso eficiente da terra (UET) para cultivares de soja reagentes quando associados ao cultivar de soja Cobb, simulador de plantas daninhas dicotiledôneas. EEA/UFRGS, Eldorado do Sul-RS, 2002/03

\begin{tabular}{|c|c|c|c|c|}
\hline \multirow{2}{*}{ Cultivar reagente } & \multicolumn{4}{|c|}{ Índice de uso eficiente da terra } \\
\hline & $\mathrm{UET}_{\mathrm{r}}{ }^{1 / /}$ & $\mathrm{UET}_{\mathrm{s}} 2 /$ & UET da associação ${ }^{3 /}$ & Contribuição relativa $(\%)^{4 /}$ \\
\hline IAS 5 & $0,343 \mathrm{c}^{5 /}$ & $0,503 \mathrm{a}$ & $0,845 \mathrm{ab}$ & $41 \mathrm{c}$ \\
\hline BR-16 & $0,523 \mathrm{~b}$ & $0,253 \mathrm{bc}$ & $0,777 \mathrm{~b}$ & $67 \mathrm{ab}$ \\
\hline CD 205 & $0,696 \mathrm{a}$ & $0,206 \mathrm{c}$ & $0,901 \mathrm{a}$ & $77 \mathrm{a}$ \\
\hline Fepagro RS-10 & $0,468 \mathrm{bc}$ & $0,360 \mathrm{~b}$ & $0,828 \mathrm{ab}$ & $57 \mathrm{~b}$ \\
\hline Médias & 0,507 & 0,331 & 0,838 & 60 \\
\hline Coeficientes de variação (\%) & 17,2 & 21,2 & 6,4 & 14,4 \\
\hline
\end{tabular}

${ }_{1 / /}$ UET parcial do cultivar de soja reagente à competição do simulador; ${ }^{2 /}$ UET parcial do cultivar simulador; ${ }^{3 /} \mathrm{UET}^{2}=\mathrm{UET}_{\mathrm{r}}+\mathrm{UET}_{\mathrm{s}} ;$ ${ }^{4 /}$ Contribuição relativa do cultivar de soja reagente para o UET total da associação com o cultivar Cobb; ${ }^{5 /}$ Médias seguidas de mesma letra, nas colunas, não diferem entre si pelo teste de Duncan a 5\% de probabilidade. 
Evidencia-se, através dos resultados obtidos, que a competição entre indivíduos de mesma espécie foi elevada, refletindo-se na produtividade de grãos dos cultivares. A habilidade competitiva, contudo, não se relaciona apenas com características como estatura de planta e ciclo, havendo outras que também contribuem para a rápida ocupação do nicho, como, por exemplo, a habilidade em explorar precocemente recursos do solo (Radosevich et al., 1997; Liebman et al., 2001). No entanto, a maior estatura de planta, ao garantir vantagem na captação da radiação solar, evitando o sombreamento decorrente da presença de plantas concorrentes, também pode estabilizar a produtividade de grãos de cultivares de soja quando em competição com as infestantes.

Os resultados evidenciam que características dissimilares em plantas de cultivares de soja resultam em habilidade competitiva diferenciada com plantas concorrentes; plantas de soja detentoras de estatura elevada e ciclo tardio, como nos cultivares CD 205 e Fepagro RS-10, apresentam habilidade competitiva superior à daquelas de porte baixo e ciclo precoce, como de IAS 5. Ainda, plantas concorrentes de estatura elevada e ciclo tardio, como do cultivar simulador Cobb, afetam em alto grau a produtividade de grãos dos cultivares de soja, enquanto aquelas de porte baixo e ciclo precoce, como do simulador BRS 205, apresentam efeito competitivo moderado em reduzir a produtividade. Cultivares de soja portadores de habilidade competitiva superior, além de tolerarem a competição, preservando o potencial de produtividade de grãos, também causam supressão na produção de grãos das plantas concorrentes associadas.

\section{AGRADECIMENTO}

À Fundação de Amparo à Pesquisa do Estado do Rio Grande do Sul (FAPERGS) (processo n. 02/1545.0), pelo apoio financeiro na execução deste trabalho.

\section{LITERATURA CITADA}

BENNETT, A. C.; SHAW, D. R. Effect of Glycine max cultivars and weed control on weed seed characteristics. Weed Sci., v. 48, n. 4, p. 431-435, 2000.
BOARD, J. E.; WIER, A. T.; BOETHEL, D. J. Source strength influence on soybean formation during early and late reproductive development. Crop Sci., v. 35, n. 4, p. 1104-1110, 1995.

CHEMALE, V. M.; FLECK, N. G. Avaliação de cultivares de soja (Glycine max (L.) Merril) em competição com Euphorbia heterophylla L. sob três densidades e dois períodos de ocorrência. Planta Daninha, v. 5, n. 2, p. 36-45, 1982.

COSTA, J. A.; MARCHEZAN, E. Características dos estádios de desenvolvimento da soja. Campinas: Fundação Cargill, 1982. 30 p.

DONALD, C. M. In search of yield. J. Aust. Inst. Agric. Sci., v. 28, p. 171-178, 1962.

DYBING, C. D. Soybean flower production as related to plant growth and seed yield. Crop Sci., v. 34, n. 2, p. 489497, 1994.

EMPRESA BRASILEIRA DE PESQUISA AGROPECUÁRIA - EMBRAPA. Sistema brasileiro de classificação de solos. Brasilia: 1999. 412 p.

LIEBAMN, M. T.; MOHLER, C. L.; STAVER, C. P. Ecological management of agricultural weeds. Cambridge: University Press, 2001. 532 p. Cap. 6: Enhancing the competitive ability of crops.

JANNINK, J. L. et al. Index selection for weed suppressive ability in soybean. Crop Sci., v. 40, n. 4, p. 1087-1094, 2000.

JUAN, V. F.; SAINT-ANDRE, H.; FERNANDEZ, R. R. Competencia de lecheron (Euphorbia dentata) en soja. Planta Daninha, v. 21, n. 2, p. 175-180, 2003.

RADOSEVICH, S.; HOLT, J.; GHERSA, C. Weed ecology: implications for vegetation management. 2.ed. New York: Wiley, 1997. 589 p. Cap. 5: Associations of weeds and crops; cap. 6: Physiological Aspects of Competition.

REGNIER, E. E.; STOLLER, E. W. The effects of soybean (Glycine max) interference on the canopy architecture of common cocklebur (Xanthium strumarium), jimsonweed (Datura stramonium), and velvetleaf (Abutilon theophrasti). Weed Sci., v. 37, n. 2, p. 187-195, 1989.

RIBOLDI, J. Delineamentos experimentais de campo. Porto Alegre: Instituto de Matemática da UFRGS, 1993. 71 p. (Cadernos de matemática e estatística).

INSTITUTE STATISTICAL ANALYSIS SYSTEM - SAS. User's guide: version 6.4. ed. Cary: SAS Institute, 1989. $846 \mathrm{p}$. 